\title{
Challenges of Change: A Qualitative Study of Chronic Care Model Implementation
}

\author{
Mary C. Hroscikoski, MD, $M S^{1}$ \\ Leif I. Solberg, $M D^{1}$ \\ JoAnn M. Sperl-Hillen, $M D^{1}$ \\ Peter G. Harper, MD, MPH \\ Michael P. McGrail, MD ${ }^{2}$ \\ Benjamin F. Crabtree, $\mathrm{PbD}^{3}$ \\ 'HealthPartners Research Foundation, \\ Minneapolis, Minn \\ ${ }^{2}$ HealthPartners Medical Group, \\ Minneapolis, Minn \\ ${ }^{3}$ Robert Wood Johnson Medical School, \\ New Brunswick, NJ \\ Shr \\ MORE ONLINE \\ www.annfammed.org
}

\begin{abstract}
PURPOSE The Chronic Care Model (CCM) provides a conceptual framework for transforming health care for patients with chronic conditions; however, little is known about how to best design and implement its specifics. One large health care organization that tried to implement the CCM in primary care provided an opportunity to study these issues.
\end{abstract}

METHODS We conducted a qualitative, comparative case study of 5 of 18 group clinics 18 to 23 months after the implementation began. Built on knowledge of the clinics from a previous study of advanced access implementation, data included in-depth interviews with organizational leaders and varied clinic personnel, observation of clinic care processes, and review of written materials.

RESULTS Relatively small and highly variable care process changes were made during the study period. The change process underwent several marked shifts in strategy when initial efforts failed to achieve much and bore little resemblance to the change process used in the previously successful large-scale implementation of advanced access scheduling. Many barriers were identified, including too many competing priorities, a lack of specificity and agreement about the care process changes desired, and little engagement of physicians.

CONCLUSION These findings highlight specific organizational challenges with health care transformation in the absence of a blueprint more specific than the CCM. Effective models of organizational change and detailed examples of proven, feasible care changes still need to be demonstrated if we are to transform care as called for by the Institute of Medicine.

Ann Fam Med 2006;4:317-326. DOI: 10.1370/afm.570.

\section{INTRODUCTION}

$\mathrm{P}$ roviding optimal health care for persons with chronic conditions is a major concern in the United States. The Institute of Medicine (IOM) reports that the care delivered is frequently not the care that patients should receive given current medical knowledge. ${ }^{1}$ The IOM has called on health care organizations to "design and implement more effective organizational support processes to make change in the delivery of care possible." ${ }^{\prime \prime}$ The same themes have been called for by the Future of Primary Care conference and the Future of Family Medicine project. ${ }^{2,3}$

In line with these recommendations, the Chronic Care Model (CCM) conceptualizes care as prepared practice teams in productive interactions with informed, activated patients (Figure 1). Six elements appear important for this end: the (1) overall health care organization, which must support a (2) redesigned delivery system and (3) modern clinical information systems $_{i}(4)$ systematic decision support $_{i}(5)$ self-management support for patients; and (6) links to available community resources. ${ }^{4,5}$

Multidisciplinary practice teams are key to the CCM, but they require substantial redesign and reorientation from the existing care roles and processes that are oriented toward acute care. Successful teams are created 
through formulating multifaceted goals and related measurable outcomes, systematizing routine tasks of care, making member tasks and roles explicit, providing appropriate training, and substituting nonphysician for physician tasks when appropriate. ${ }^{6}$

Though the CCM is well developed as a conceptual framework, there are no specific steps, methods, or existing models to guide medical groups wanting to implement it. Groups must figure out what the parts look like and how to make them come together as a whole. This challenge was encountered by a large multispecialty group in Minneapolis-St. Paul when in 2001 it chose to make CCM implementation in primary care a cornerstone of its care improvement efforts.

The purpose of this article is to describe this medical group's effort to address the challenge of implementing a CCM-type change so that others might learn from its experience. Our study, designed to evaluate both the care system changes addressed and the change process used to implement them, focused on the following questions:

1. Which CCM components were being addressed, and how well were they implemented?

2. What change process strategies were used, both centrally and at individual clinic sites?

3. What important facilitators or barriers were encountered?

4. What generalizable lessons and recommendations can be drawn from this experience?

\section{Figure 1. The Chronic Care Model.}

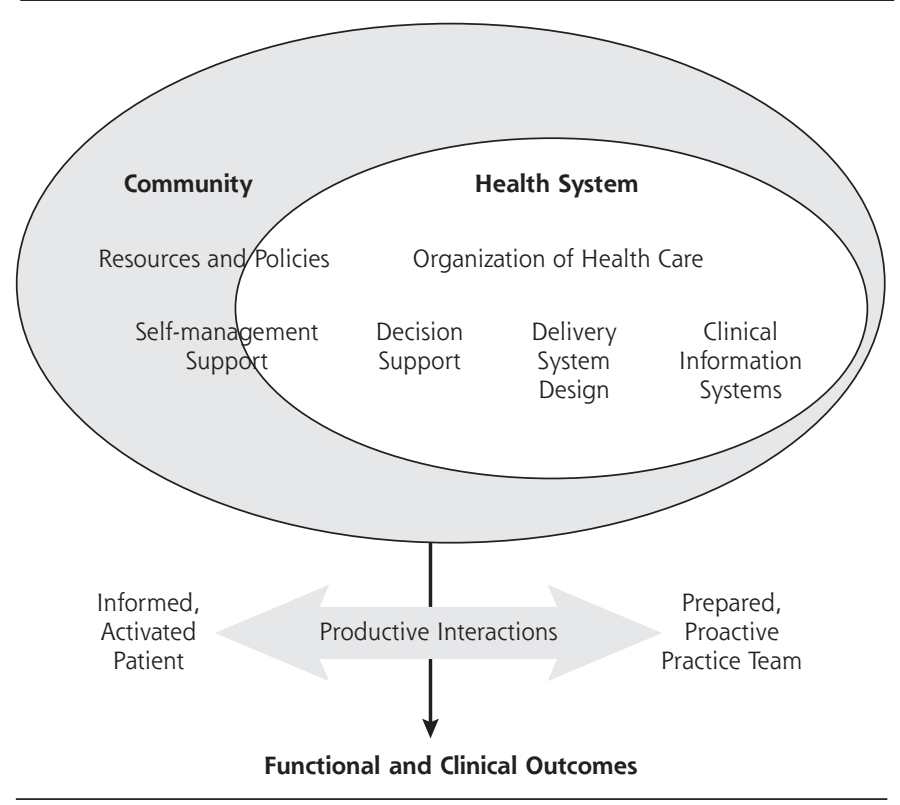

Wagner EH. Chronic disease management: What will it take to improve care for chronic illness? Eff Clin Pract. 1998;1:2-4. Reprinted with permission of the American College of Physicians. http://improvingchroniccare.org.

\section{METHODS}

\section{Preintervention Context}

This 600-physician multispecialty group was described in the preceding companion article. ${ }^{7}$ The group overall was led by a medical director and senior administrator, supported by a council of medical and administrative leaders. It had successfully achieved a major care transformation in implementing an advanced access patientscheduling system throughout these clinics in $2000 .^{8}$

The group also has had certain CCM elements in place for some time, particularly guidelines, patient education, chronic disease registries, and standing orders for preventive services.

Before instituting advanced access scheduling, the medical group was relatively decentralized in its functioning, and individual clinics, as well as individual physicians, worked with relative autonomy. Clinics had little systematization of care and few designated leadership roles. The advanced access change process led to strengthened central and clinic leadership, plus more centralization of authority and lessened clinic and physician autonomy. ${ }^{8}$

\section{The Intervention}

Organizational leaders chose more complete implementation of the CCM as a major priority for 2002, and later impetus was stimulated by a grant award from the Robert Wood Johnson Foundation and the Institute for Healthcare Improvement intended to spur care transformation. A project leader and various multidisciplinary design teams were created to guide the effort, with particular focus on access, diabetes care, and depression care. The design teams developed a plan for more systematic care processes, and individual pilot care teams were designated in several different clinics to test the implementation. Once the new care processes had been tried for a time, efforts were made to spread the approach from the pilot teams to their entire clinics, but any care changes were largely limited by existing care patterns. Simultaneously, an electronic medical record (EMR) information system was rolled out in stages, along with improvements in decision support and self-management support.

By mid-2002 the change strategy shifted from a condition-specific to a condition-neutral focus that would apply across chronic conditions, and from pilot teams to 2 small primary care clinics as research and development sites. A 2-day intensive design process developed new patient care flows by conceptualizing a 4 -stage office visit process: 
previsit, visit, postvisit, and between visits. Prepared practice teams (PPTs) were made up of a clinician and rooming nurse and were supplemented by a registered nurse and a receptionist who were shared among 3 contiguous PPTs. Although this core PPT was understood as having an expanded version that included other clinicians, implementation work focused largely on the core team.

In April 2003, concerned about the slow pace of change in these sites, medical group leaders expanded this PPT and care flow concept throughout all the primary care clinics. They brought teams from all clinics together for a 1-day collaborative meeting to explain PPT roles and tasks. Though the overall change model was still conceived in condition-neutral terms, clinics were asked to select diabetes care, depression care, or preventive services as a focus for change measurement. During later sessions at each clinic, more-detailed templates of suggested PPT roles and tasks were promoted. Most ideas were for face-to-face work, although clinics that were further along in EMR implementation and skills were beginning to think in terms of virtual teamwork as well.

In sum, the CCM implementation effort relied on medical group leaders to specify change aims and strategies, the details of which changed several times from 2002 to 2004. The change process began by focusing pilot work on a few clinics and then shifted to involve all clinics. It included expert design teams, rapid design processes, shared learning, and implementation planning by clinics in 3 multiclinic 1-day collaborative meetings; each clinic was expected to undertake its own approach to implementation. Clinic work was supported by 3 facilitators, some communication by e-mail and telephone, and monthly progress reports to project leaders. Consultants from the Institute for Healthcare Improvement provided input and external evaluation.

\section{Evaluation Approach}

This study of the above change effort was designed to build on knowledge acquired through a previous qualitative evaluation of this group's successful implementation of advanced access, and we used extensive interviews and observations at both central leader and clinic levels. ${ }^{8}$ We purposefully sampled 5 clinics from the original 18 for a diverse range of size, location, diabetes care performance, and medical group leaders' assessment of their preliminary CCM efforts. In particular, we looked for some clinics that would better exemplify change barriers, as well as for those that would better exemplify change facilitators.

One author $(\mathrm{MH})$ conducted 45 semistructured interviews with organizational leaders, external and internal change leaders, midlevel clinic managers, medical and administrative clinic leaders, front-line physicians, and nurses (53 persons). Questions focused on actual care changes, the change processes used, and perceived change facilitators and barriers. Descriptive field notes of observed work in patient care areas, with special attention to PPT activities, helped in triangulating interview findings. ${ }^{9}$ Institutional Review Board approval was obtained. The interviews and observations were conducted during a 5 -month period, beginning 18 months into the overall CCM implementation and 6 months after systematic PPT work started in the clinics.

All interviews were tape-recorded, transcribed, and combined with typed observation notes for review by the first 5 coauthors. Immersion-crystallization and iterative consensus processes were used to develop the analysis and interpretation. ${ }^{10,11}$ We sought disconfirming

\section{Table 1. Clinic Sample Description}

\begin{tabular}{|c|c|c|c|c|c|}
\hline \multirow[b]{2}{*}{ Characteristic } & \multicolumn{5}{|c|}{ Clinic } \\
\hline & 1 & 2 & 3 & 4 & 5 \\
\hline Membership size* & Medium & Medium & Large & Medium & Small \\
\hline $\begin{array}{l}\text { Condition focus selected } \\
\text { for improvement }{ }^{\dagger}\end{array}$ & Diabetes & Diabetes & Depression & Depression & Diabetes \\
\hline $\begin{array}{l}\text { Diabetes mellitus care } \\
\text { performance }\end{array}$ & No rating & No rating & Strong or improved & Strong or improved & Strong or improved \\
\hline $\begin{array}{c}\text { Progress in initial phases } \\
\text { of the CCM change }\end{array}$ & Some & No rating & More & More & More \\
\hline $\begin{array}{l}\text { Self-report of initial PPT } \\
\text { success vs challenges" }\end{array}$ & Success > challenges & Success < challenges & Success $=$ challenges & Success < challenges & Success $=$ challenges \\
\hline \multicolumn{6}{|c|}{$\begin{array}{l}\text { * Small is }<7,000 \text { members, medium is } 7,000 \text { to } 16,000 \text {, and large is }>16,000 \text {. } \\
\text { † See Methods. Clinics were asked to select diabetes, depression, or preventive services as a focus for change progress toward the CCM. } \\
\text { f Based on } 2002 \text { diabetes care improvement data collected routinely by the medical group, a combined measure of patients with both A1c and low-density } \\
\text { lipoprotein values up to date and in control. }\end{array}$} \\
\hline
\end{tabular}


evidence in the data during the course of analysis discussions. Informant recall bias could not be measured specifically but was dealt with through triangulating multiple informant interviews, existing organizational documents, and the perspectives of 2 team members who were also organizational and change leaders (LIS, JSH).

We rated the level of CCM implementation at each clinic using a categorization developed by RAND. ${ }^{12}$ We looked at the highest level of CCM activity within each clinic, whether it was done generally or focused on a specific condition (typically diabetes care or depression care), and scored the presence of components for each CCM element according to a 3-point scale (Table 2, and Supplemental Table, avail-

able at: http://www.annfammed.org/cgi/content/

in full/4/317/DC1). For example, for the clinic with only 1 officially designated pilot PPT, we scored that team's activity rather than trying to contrive an average score across nonexistent or minimally existent teams. Thus, this scoring tended to overestimate the extent of CCM implementation.

\section{RESULTS}

\section{Care Process Changes}

A number of similarities were evident across the 5 clinics studied. All showed at least some evidence of PPT development with a new sense of team identity and teamwork. The roles of registered nurses now included varying amounts of team and patient care management. Focused attention was being given to previsit planning, including systematically reviewing and collating test results, identifying preventive and other clinical services needed, comparing care with established guidelines, and providing alerts for items needing attention at the visit. At some clinics, subgroups of patients were called to come in for previsit laboratory work.
Despite these similarities, the differences among and within clinics were pronounced. For example, PPT structure and function varied widely. The centrally recommended design of 4 core PPT members had been adopted by 3 of the 5 clinics. Another clinic added a fifth team member from the chartroom staff, and still another clinic designated all geographically adjacent personnel as a PPT (10 to 12 members). Clinics and teams differed in their team leadership, and few involved the clinician more than peripherally. Team function across and within clinic sites seemed to be more dependent on individual personalities than on systematically planned and similar team roles.

Regardless of the specific membership, finding team meeting times was a universal logistic challenge, because work schedules varied, clinic staffing was lean, and many found it difficult to take time from more routine patient care responsibilities. Although all PPTs were doing some previsit planning, there was little standardization of care across PPTs or clinics. Registered nurse and clerical roles changed the most, with registered nurses often becoming de facto PPT leaders and doing some care management. Clerical assistants in some clinics helped with calling patients to come in for previsit laboratory work, and in most clinics at least part of their work was in physical proximity to the registered nurses and licensed practical nurses, in contrast to previous physical separation. The licensed practical nurses working in tandem with physicians showed fewer role changes.

Nonphysician staff commonly expressed appreciation for the newfound teamwork and the opportunity to be more involved in patient care.

"This clinic is awesome, and what they've done is incredible. Everything just feels and flows so much bet ter. You notice that things are much smoother. There isn't a lot of that chaotic sort of running around. Not that they're not busy-they are incredibly busy here. People work hard, but they get through the day, and

Table 2. Chronic Care Model (CCM) Implementation Scoring

\begin{tabular}{|c|c|c|c|c|c|c|c|}
\hline \multirow[b]{2}{*}{$\begin{array}{l}\text { CCM Element (No. of } \\
\text { Components) }\end{array}$} & \multirow[b]{2}{*}{$\begin{array}{l}\text { Points } \\
\text { Possible* }\end{array}$} & \multicolumn{5}{|c|}{ Clinic } & \multirow[b]{2}{*}{$\begin{array}{l}\text { Mean } \\
\text { Scores }\end{array}$} \\
\hline & & $\begin{array}{c}1 \\
\text { No. }(\%)^{\dagger}\end{array}$ & ${ }^{2}{ }^{2}(\%)^{\dagger}$ & No. ${ }^{3}(\%)^{\dagger}$ & $\begin{array}{c}4 \\
\text { No. }(\%)^{\dagger}\end{array}$ & No. $(\%)^{\dagger}$ & \\
\hline Delivery system redesign (6) & 12 & $2(17)$ & $5(42)$ & $6(50)$ & $6(50)$ & $9(75)$ & $5.6(47)$ \\
\hline Self-management support (6) & 12 & $2(17)$ & $2(17)$ & $2(17)$ & $1(8)$ & $5(42)$ & $2.4(20)$ \\
\hline Decision support (3) & 6 & $0(0)$ & $2(33)$ & $3(50)$ & $1(17)$ & $3(50)$ & $1.8(30)$ \\
\hline Clinical information systems (3) & 6 & $0(0)$ & $1(17)$ & $0(0)$ & $2(33)$ & $4(67)$ & $1.4(23)$ \\
\hline Community linkages (2) & 4 & $0(0)$ & $0(0)$ & $0(0)$ & $0(0)$ & $0(0)$ & $0.0(0)$ \\
\hline Health care organization (3) & 6 & $1(17)$ & $0(0)$ & $0(0)$ & $1(17)$ & $2(33)$ & $0.8(13)$ \\
\hline Total & 46 & $5(11)$ & $10(22)$ & $11(24)$ & $11(24)$ & $23(50)$ & $12.0(26)$ \\
\hline \multicolumn{8}{|c|}{$\begin{array}{l}\text { Note: Scores are reported here at the CCM element level. For scoring at the element component level, see the expanded version of Table } 2 \text { in the online-only Supp } \\
\text { mental Table. }\end{array}$} \\
\hline
\end{tabular}


it just feels much more efficient than I think how we operated even 5 years ago. So it's a good place. What's made the difference is the teamwork" (Supervisor, clinic 3: interview 1).

"It was clear to me that there was a very different energy in this group compared to my visit 2 years ago for the advanced access evaluation. Then, I remember a sense of strain about the struggles of the changes that had already taken place and anticipation of major struggles around changes yet to come. The sense this time was that those changes had been successfully negotiated, and that there was a certain comfort about the workings of things. I also sensed that this leadership team seemed very comfortable and at ease with each other" (Interviewer's notes, clinic 3).

On the other hand, clinic leaders, especially in the smaller clinics, expressed concern that slim staffing margins and inflexible job descriptions limited their ability to innovate work roles.

Among the clinic similarities, the most striking was that physician roles were generally unchanged. Although certain physicians were actively involved with the changes either as named or as de facto leaders, by and large, change happened around the physicians and did not depend on their participation or engage them in a meaningful way. At least in part, this lack of engagement appeared related to the tradition and organizational history of physician autonomy.

Physician opinions about the value of previsit planning also varied. Some believed that PPT previsit work enabled them to make therapeutic moves with patients more quickly and easily (eg, intensifying diabetes medications).

"The visits are easier because you have the information that you need, and you can do a lot more with the visit. You can save a lot of time and actually go on to more important issues from the patient's perspective and also on changing the treatment, starting new medications, and adjusting them" (Physician, 5:2).

Others believed that such planning made no difference, because patient noncompliance was the chief constraint for any care improvement.

"Having information at the time that you're actually seeing the patient changes the flow in the office a lot, about when things get done or who's calling about what. But we haven't fundamentally changed how we motivate people. We're just pestering them on a different end of that visit" (Physician, 2:5).

Such comments seemed to reflect a lack of awareness of the need for any systemic care change, as well as the common medical professional pattern of blaming patients for the ills of their care results. ${ }^{13}$

In several of the clinics, structural space changes positioned PPT members closer together, which their leaders observed had improved team function. In clinics where floor plans remained traditional (clerical staff at front, licensed practical nurses in the middle near examination rooms, individual physician offices in back, and registered nurses in a separate space), teamwork appeared constrained by the geography. Traditional workspace arrangements, in effect, segregated clinic staff by work discipline and did not provide shared, comfortable spaces for face-to-face multidisciplinary teamwork. Although a fully functioning EMR could provide a shared virtual workspace, at the time of our study, most clinics were still too new to electronic systems to use them facilely.

Information systems were an important element of the CCM implementation in 2 major ways. First, the 2-phase organizational implementation of an EMR, initially mostly read-only but later fully interactive and paperless, was concurrent with other aspects of CCM implementation. The demands of learning computer skills and using the new EMR reduced the ability to focus more specifically on team and care changes, at times overwhelming all personnel. Second, the initial read-only EMR disrupted existing care processes, including flow sheets and registries. It did not permit easy collation of information necessary for care planning, such as flow sheets of preventive services. It also did not accommodate the importation or customization of tools for information management. Information management for planning and following patterns of clinical care often required a great amount of reworking by the staff. In addition, the use of existing online chronic disease registries, eg, for diabetes, varied widely across the clinics. The clinic with best use of a registry had a software-savvy administrative leader who customized their registry report to make it more user-friendly, even though it required double entry of data. The 2 clinics that did not use the registries at all reported they chose not to because the cost of reworking information led to inaccuracies that were greater than the potential benefits.

"I think registry lists never flew. We tried working. We got registry lists from corporate. By the time you got them, they were based on billing data, they were wrong, and it felt like just a tremendous waste of time to try and work that list. We had to clean it up and then work it. It was just a ridiculous waste of time and no return" (Supervisor, 1:1).

Organizational leaders agreed that clinic operations were changing but believed that care practices were not being dramatically transformed. At the time of the interviews, they were not expecting much change in patient outcomes soon. There were struggles in developing adequate change measures and little means for accountability. Nevertheless, many spoke of their hope 
for achieving change in the future, using such metaphors as a "foundation being laid," a "plane ready for take off," or being "ready to blossom."

The level of CCM implementation in each clinic, as rated by the authors from the interview and observational data, is displayed in Table 2 . These findings illustrate the relatively low level of implementation of the CCM elements and their components 2 years into the process, even in the one clinic that was much more successful in doing so. PPT development, hence delivery system redesign, was the focus of most of this CCM implementation effort. Clinical information systems and health care organization were the other CCM elements with some notable changes. Scores in the self-management support and decision support categories more often related to tools and practices that predated the CCM implementation.

\section{Change Process}

The change process used to implement these care process changes was strikingly different from what had been used for the successful implementation of advanced access scheduling 2 years earlier. Table 3 summarizes these differences, most of which appeared to be related to the much less well-defined informa- tion available about details or methodology of CCM implementation. As a result, every clinic went about change differently. Local clinic leader approaches ranged from hands off to micromanaging, but mostly they relied on the self-organizing initiative of individuals and each PPT.

Originally, it was hoped that substantial transformation of care could be made within 1 year, but it quickly became apparent this much was not possible. Change strategies required major revision and time. As 1 organizational leader said, "We are limited by human capacity to change [and] we are rebuilding the airplane while it's flying."

\section{Change Facilitators and Barriers}

Change facilitators and barriers at both clinic and organizational levels are summarized in Table 4. Notable facilitators included the presence of a few strong clinic leaders, such as a chief physician who envisioned the specific changes needed and supervisors who supported that vision. Clinic staff able to take leadership of PPTs became important change leaders for individual teams. In other words, leadership ability needed to be dispersed over multiple levels that ranged from overall clinic leaders to at least some clinic staff

\begin{tabular}{|c|c|c|}
\hline Dimension & Advanced Access & Chronic Care Model \\
\hline Desired state description & $\begin{array}{l}\text { Clear, simple, predefined, understandable, prescriptive- } \\
\text { many examples of what others have done }\end{array}$ & $\begin{array}{l}\text { Theoretical, complex, composite of pieces from } \\
\text { various settings-no overall examples or models }\end{array}$ \\
\hline Change benefits & Simplifies work of clinician, staff, and patient & Effects on stakeholders are as unclear as the model \\
\hline $\begin{array}{l}\text { Overall focus of the } \\
\text { organization }\end{array}$ & Concentrated on this change effort & Diffused over multiple priorities \\
\hline Leadership role & $\begin{array}{l}\text { Main priority for that year with high visibility, and many } \\
\text { dedicated resources }\end{array}$ & $\begin{array}{l}\text { Many simultaneous changes and priorities, the larg- } \\
\text { est being EMR implementation }\end{array}$ \\
\hline Communication & $\begin{array}{l}\text { Multiple avenues with frequent and specific messages } \\
\text { and reports from and to leadership }\end{array}$ & $\begin{array}{l}\text { Frequent from leadership, limited in explaining } \\
\text { shifting strategies; few avenues for clinic team } \\
\text { feedback to central leaders }\end{array}$ \\
\hline Timeline & Clear endpoint in 1 year & $\begin{array}{l}\text { Beginning of a long process without definite } \\
\text { endpoints }\end{array}$ \\
\hline External experts & $\begin{array}{l}\text { Experienced with many other groups, knowledgeable } \\
\text { about specifics, and available at local collaboratives, } \\
\text { conference calls, and an ongoing listserv (medical group } \\
\text { also provided expertise, eg, measurement, to experts) }\end{array}$ & $\begin{array}{l}\text { Primarily theoretical consultants available only to } \\
\text { leaders; no actionable blueprint of an imple- } \\
\text { mented, functional CCM available }\end{array}$ \\
\hline Pilots & Proved in 3 sites & Unclear process and results in 3 to 4 sites \\
\hline Testimonials & Videos of newly converted skeptics & Individual comments at meetings \\
\hline Measurement & $\begin{array}{l}\text { A few simple, visible, repeated measures of problems and } \\
\text { progress }\end{array}$ & $\begin{array}{l}\text { Difficult to develop, varied, transient, with limited } \\
\text { connection to process changes }\end{array}$ \\
\hline Local change management & $\begin{array}{l}\text { Specified local teams with clear tasks and responsibility } \\
\text { to tailor implementation }\end{array}$ & $\begin{array}{l}\text { Largely dependent on self-organizing abilities } \\
\text { within clinics }\end{array}$ \\
\hline $\begin{array}{l}\text { Multiclinic collaborative } \\
\text { learning sessions }\end{array}$ & $\begin{array}{l}\text { Quarterly meetings of all clinics' teams, with follow-up } \\
\text { through listserv and conference calls }\end{array}$ & $\begin{array}{l}\text { Three meetings of clinic teams to learn latest } \\
\text { change in strategy }\end{array}$ \\
\hline Learning session follow-up & $\begin{array}{l}\text { Listserv and conference calls have profound and immediate } \\
\text { results, related to concrete, specific content of changes }\end{array}$ & $\begin{array}{l}\text { Listserv has limited impact, related to fuzzy content } \\
\text { of changes }\end{array}$ \\
\hline Local accountability & $\begin{array}{l}\text { Monthly reports required and each clinic's data and sta- } \\
\text { tus public }\end{array}$ & $\begin{array}{l}\text { Periodic oral or written reports-public measures } \\
\text { available but have limited impact }\end{array}$ \\
\hline
\end{tabular}


in varying roles. Physicians, even though not engaged, did not openly resist the care changes, because those changes that affected the availablilty of information and supported decision making made their lives easier. In some clinics, personnel actions were taken with those unwilling to make changes, including physicians; these decisions were typically made at the clinic level and supported by central leaders. At 1 clinic, supervisors believed such an action was the difference that allowed teamwork development to proceed. We heard no evidence of such changes being a disincentive for change. As new forms of teamwork developed, the trust, communication, and stable work relationships it promoted were self-reinforcing.

Barriers to change included clinic leaders who failed to develop a practical vision for the change or who involved themselves less in change management. Change management skills appeared limited across all the clinics, and few clinics had organized change management teams. There was little, if any, evidence of meaningful use of formal change processes, such as PDSA (plan, do, study, act) cycles. Staff experienced change fatigue and apathy, the result of 4 years of major changes and many other priorities for quality improvement, productivity increases, and cost reduction. Large organizational size meant clinic personnel were relatively insulated from the business imperatives for change that could motivate a smaller group. In addition, union rules placed constraints on how work roles might be reconfigured. There was still no generally agreed-on sense that consistency or standardization of care within or across clinics was valuable.

"I don't think that the culture at the clinic has really bought into the fact that there are some best ways to do things and we should all do them that way. Even around immunizations, let's say. I had a nurse just recently who said, 'I don't think we'll ever all recommend the same thing.' Wow! That's amazing, isn't it?" (Physician leader, 2:1).

Finally, the seeming contradiction of naming physicians as both change facilitators and barriers (Table 4) reflects their professional power in shaping patient care processes and their general stance of neutral autonomy in this change. They neither actively supported nor actively resisted the change, so other clinic staff strategically built change around them. The issue of physician autonomy and general lack of engagement in the change process was not addressed systematically.

\section{Table 4. Comparison of Change Facilitators and Barriers}

\begin{tabular}{|c|c|c|}
\hline Level & Facilitators (Where Present) & Barriers (Where Present) \\
\hline Clinic & $\begin{array}{l}\text { Strong clinic leadership } \\
\text { Chief physicians as role models for chronic care and } \\
\text { doing change } \\
\text { Supervisor support of this work } \\
\text { Development of teams } \\
\text { Enhancement of trust and communication } \\
\text { Promotion of stable work relationships } \\
\text { Strong RN leadership of PPT teams and their work } \\
\text { Physicians' passive assent to change } \\
\text { Previsit work by nurses and clerical staff, making life } \\
\text { easier for physicians } \\
\text { Staff unwilling to change leave clinic } \\
\text { Natural changes (clinic remodeling, EMR implemen- } \\
\text { tation) that force changes in work relationships and } \\
\text { flows }\end{array}$ & $\begin{array}{l}\text { Physician, staff, and clinic cultures not supportive of the desired } \\
\text { changes } \\
\text { Chief physicians relatively uninterested in or uncommitted to chronic } \\
\text { care and the CCM } \\
\text { Variable, often limited, leadership guidance of PPT development } \\
\text { Few systematic change skills, strategies, or structures } \\
\text { No standardization of PPT work flows (within and across clinics) } \\
\text { No agreement on need for care standardization } \\
\text { Physicians generally not engaged in the change process; change is } \\
\text { built around them } \\
\text { Large medical group size that filters and buffers external change } \\
\text { motivators, eg, business competition } \\
\text { Demands of simultaneous EMR implementation } \\
\text { Union rules inhibit role changes } \\
\text { Clinic staff are accountable to supervisors, not to physicians } \\
\text { Change fatigue and apathy resulting from recent scope and pace of } \\
\text { changes }\end{array}$ \\
\hline $\begin{array}{l}\text { Organization } \\
\text { leaders }\end{array}$ & $\begin{array}{l}\text { Clear articulation of a new conceptualization of the } \\
\text { care cycle (previsit, visit, postvisit, between visit) } \\
\text { Awareness of clinic attitudes and actions } \\
\text { Clear, shared, and long-term commitment to need } \\
\text { for change } \\
\text { Flexible strategies for change } \\
\text { Realistic expectations for minimal early measurable } \\
\text { results } \\
\text { Recognized need to change the foundation before } \\
\text { building the house }\end{array}$ & $\begin{array}{l}\text { Organizational culture not supportive of the desired changes } \\
\text { Lack of specific details and examples of desired care changes } \\
\text { Broad scale of change required, encompassing multiple organizational } \\
\text { facets } \\
\text { Too many simultaneous priorities and changes } \\
\text { Change goals and outcomes unclear } \\
\text { Change process fuzzy and uncoordinated } \\
\text { Lack of useful measures of change with periodic measurement } \\
\text { Added complexities of grant funder expectations and distractions } \\
\text { Leaders face multiple uncertainties and distractions, leading to limited } \\
\text { change prototypes and measures, limited push, and accountability }\end{array}$ \\
\hline
\end{tabular}




\section{DISCUSSION}

This medical group's effort to transform its approach to care by implementing CCM concepts appears to have produced some changes, mostly related to partial changes in team structure, roles, and function, as well as introduction of an EMR. Although the team changes appeared small, immensely varied within and among its clinics, and unlikely to be associated with major measurable improvements in care, they may represent a first step in creating a new foundation for transformed care. They illustrate that changing traditional care patterns is difficult and requires enormous attention and focus, with clear specifications, strong leadership, and attention to a myriad of details at both local and central levels of an organization.

The companion article, describing the related quantitative quality measure results from our study, shows that the improvements for diabetes care, coronary heart disease care, and depression care occurred in outcomes (such as glycated hemoglobin and low-density lipoprotein levels) rather than in care processes (such as rates of laboratory testing or use of antidepressant medications). ${ }^{7}$ This qualitative work suggests that the care process changes were still nascent, and the care improvements may not have been directly due to the CCM implementation. The quality measure improvements during the CCM change may also be taken as a hopeful sign that long, difficult, and sometimes chaotic change processes are not incompatible with some advances in care quality.

It is particularly striking to compare the approaches taken for this change effort with those taken for advanced access 2 years earlier. At first glance it looks as if the organization forgot the change lessons of its earlier successful transformation. The differences become more understandable, however, with the realization that the 2 changes were qualitatively different, beginning with care process designs, which differed completely in their level of action and ability.

The advanced access effort began with a more concrete, prescriptive model ready for implementation, whereas the CCM effort had only an abstract conceptual framework that required up-front design of what was to be implemented and how to do it. The CCM change leaders also had to adjust to constrained options because of the grant and other organizational priorities. As a result, their strategies changed several times as they worked to construct and flesh out operational details of the CCM concept and its implementation. Clinic leaders then often had limited guidance on what to do and how to do it. Although the medical group is known for its measurement savvy, meaningful measures and feedback mechanisms for the changes were also difficult to develop. Much of the change effort aimed for endpoints in work relationships, where it appeared that measurable processes did not necessarily translate into desired, measurable outcomes. Measure development was also hampered at the time of the study by a limited understanding of the PDSA process in the clinics and by so few changes being systemwide, and thus amenable to systemic measurement. This example highlights the difference between theoretical ideals and practical realities. In an ideal world, it might have been easier to separate EMR implementation from PPT development. Leaders wondered in retrospect whether it would have been easier for clinics to be plunged into the interactive EMR from the start, rather than have it implemented in stages. But in the real world, decisions must be made and action taken on the basis of incomplete information. Regardless of how planned any change may be, no one has the luxury of planning its full context or its related contingencies free of other priorities. In addition, one structural change may bring to the fore others needing to happen, as with the problematic registries that led to staff work-arounds.

This example also raises questions about how best to use the conceptual framework, the Chronic Care Model, particularly in regard to the difference between care process design and change implementation. After initial efforts to educate clinic personnel in the overall framework clearly failed, organizational leaders turned from using the whole CCM to a few more-focused concepts, especially PPTs. Although they developed some role specifications for PPT members, individual teams and clinics had to work out their own details. With no preexisting examples of effective teams, we observed that the teams had limited effectiveness and undesirable variability. The main improvements came from those personnel most prepared for role expansion, particularly nurses, who used the opportunity to develop their immediate care setting.

As a conceptual framework, the CCM is useful for thinking about the types of care processes needing to be addressed. It was at best a vague guide to change, however; there were no specifics about the actual care process changes to be made and no description of the change process needed to achieve them. In contrast, Murray and Tantau's detailed description of a more limited but still dramatic change in care process-advanced access-does provide those operational specifics. ${ }^{14-16}$ In addition to a theoretical framework for thinking about the problem, it specifies what the new care model looks like ( $>50 \%$ open appointments at the beginning of a day, offers of same-day service with one's personal clinician, etc) and what changes are needed to get there (periodic measures of backlog and access, reduction in appointment types, working down the backlog, "max-packing" visits). They also describe previous transformation experiences and successful models. This information 
allowed the medical group to successfully tailor its own approach to advanced access implementation (Table 3).

Efforts to improve the quality of medical practice have a long history, going back at least to the work of Dr Ernest Codman in the 19th century. ${ }^{17}$ More recently, we passed through the phase of quality assurance based on the "bad apple" theory, and then to the continuous quality improvement model from industry. ${ }^{18}$ After some false starts in which there was too much emphasis on improving particular processes using models that took too long and failed to involve leadership and address culture, we now seem to be developing more comprehensive and rapid approaches that include physicians. ${ }^{19}$ The research literature, however, has continued to focus almost entirely on studying interventions to change the behavior of individual physicians. ${ }^{20,21}$ Only recently are the 2 threads coming together in an understanding that real change requires applying quality improvement to change practice systems and using organizational change processes to do so. ${ }^{22-28}$

Some of the lessons we draw from this large organization's effort to transform its care for patients with chronic conditions are as follows:

1. Choose selective care processes that have been well worked out in similar settings, or devote time to careful design and piloting before tackling implementation.

2. Use the CCM as a backdrop for leaders to understand the relationships and roles of specific care changes needed, not as the change blueprint or training model.

3. Recognize and respect the difficulty of changing traditional care patterns. Organizational and professional cultures are critical to any change and require as much attention as the implementation, so first understand and align your organization's culture with the strategies being chosen. ${ }^{29}$ Attend to work relationships; when functioning well, they should engage and empower all stakeholders to invest in and contribute to the changes. ${ }^{30}$

4. Involve and engage physicians in both the care and change processes, or change will be stymied and the impact on patient outcomes will be limited.

5. Give individual clinics clear models and specifications about the desired end, as well as latitude in how they get there.

6. Provide strong leadership vision, along with change management skills, and ample resources at the level of both overall organization and individual clinics.

7. Monitor closely what is going on, and adjust as change barriers emerge.

8. Focus, focus, focus! Large changes require strong prioritization and ongoing concentration of organizational attention, resources, time, and energies.

9. Change takes time, probably twice as long as you think. Pace the work, giving time and space for essential group learning and reflection. ${ }^{31}$
10. Allow for the unexpected. Complexity science suggests that surprise is inherent in organizational change, offering as much opportunity for learning and creativity as threat of failure for those open to it. ${ }^{32,33}$

11. Appreciate that concurrent organizational changes may be unavoidable, even when it would be better to separate them.

This study is limited in being observational and including only a few clinics with varying change success within one large care system. Interviews and clinic observations were made at single points in a much longer time span of changes. In addition, although the overall change effort was intended as implementation of the CCM, it largely focused on the elements of delivery system design (PPTs) and on clinical information system changes (EMR). This medical group's experience may be best viewed as an exploration in organizational change.

Study credibility is enhanced by the research team's extensive experience in studying clinical practices and related organizational change. Key organizational leaders were also engaged with this team to strengthen our data collection and its iterative analysis. It is also important to note that each member of the research team was familiar with the CCM, had supported its use at least conceptually, and had research and/or leadership experience in changing physician behavior. Three (LIS, JSH, MPM) had some direct leadership involvement in this CCM implementation effort. Two $(\mathrm{MCH}, \mathrm{BFC})$ approached the research from a cultural anthropology perspective.

Generalizability is tempered by studying a single, large health care system in a region in which managed care and large health care organizations are widespread. Clearly, this group differs in organizational complexity, leadership, and resources from the small practices providing most of the primary care in the United States. Although the specifics of CCM use must be somewhat site, system, and population dependent, our sense is that the facilitators and barriers others might encounter in implementing the model would differ more in degree than in kind. The lessons learned here are probably applicable for any medical group interested in the CCM, especially identification of optimal PPT structures and function and optimal integration of the EMR.

A more-detailed and specific care process and change process for CCM implementation probably will be required to achieve a higher stage of evolution and any major change in care delivery. The problems and needs identified here may partially explain why there are still so few examples of the successful care changes called for by the Institute of Medicine.

\section{Epilogue}

In the 2 years since data for this study were collected, the medical group has fully implemented its EMR and 
made considerable progress in delineating and applying its standardized, disease-neutral care model and the visit cycle concept (previsit, visit, postvisit, and between-visit). This model continues to spread in primary care through clinic-wide collaborative learning sessions, and training has included leadership development. Physician engagement is being built into the EMR. Quality measures are starting to show increased improvement, and leaders are cautiously optimistic that the trend will continue.

To read or post commentaries in response to this article, see it online at http://www.annfammed.org/cgi/content/full/4/4/317.

Key words: Chronic disease; models, theoretical; organizational innovation; physician's practice patterns; quality of health care

Submitted November 2, 2005; submitted, revised, March 15, 2006; accepted March 31, 2006.

Funding support: This study was supported by grant \# 041868 from The Robert Wood Johnson Foundation through the Improving Chronic Illness Care Initiative.

Acknowledgments: This medical group made large contributions to health care improvement in its willingness to share what it learned and its resources with others. In particular, we appreciate the many medical group leaders, clinic personnel, and other change leaders who so generously participated in this study. Beth Waterman's help was especially important; also, we appreciate Marty Campbell for her invaluable help with scheduling interviews and clinic visits and with manuscript preparation.

\section{References}

1. Institute of Medicine. Crossing the Quality Chasm: A New Health System for the 21st Century. Washington, DC: National Academy Press; 2001.

2. Showstack J, Lurie N, Larson EB, Rothman AA, Hassmiller S. Primary care: the next renaissance. Ann Intern Med. 2003;138:268-272.

3. Martin JC, Avant RF, Bowman MA, et al. The Future of Family Medicine: a collaborative project of the family medicine community. Ann Fam Med. 2004;2(Suppl 1):S3-32.

4. Bodenheimer T, Wagner EH, Grumbach K. Improving primary care for patients with chronic illness. JAMA. 2002;288:1775-1779.

5. Wagner EH. The role of patient care teams in chronic disease management. BMJ. 2000;320:569-572.

6. Grumbach K, Bodenheimer T. Can health care teams improve primary care practice? JAMA. 2004;291:1246-1251.

7. Solberg LI, Crain AL, Sperl-Hillen JM, Hroscikoski MC, Engebretson $\mathrm{KI}, \mathrm{O}^{\prime}$ Connor PJ. Care quality and implementation of the Chronic Care Model: a quantitative study. Ann Fam Med. 2006;4;310-316.

8. Solberg LI, Hroscikoski MC, Sperl-Hillen JM, O'Connor PJ, Crabtree $\mathrm{BF}$. Key issues in transforming health care organizations for quality: the case of advanced access. Jt Comm J Qual Saf. 2004;30:15-24.

9. Crabtree BF, Miller WL, Stange KC. Understanding practice from the ground up. J Fam Pract. 2001;50:881-887.

10. Miller WL, Crabtree BF. The dance of interpretation. In: Crabtree BF, Miller WL, eds. Doing Qualitative Research. Thousand Oaks, Calif: Sage Publications; 1999:127-144.

11. Borkan JM. Immersion/Crystallization. In: Crabtree BF, Miller WL, eds. Doing Qualitative Research. Thousand Oaks, Calif: Sage Publications; 1999:179-194.
12. Pearson ML, Wu S, Schaefer J, et al. Assessing the implementation of the Chronic Care Model in quality improvement collaboratives. Health Serv Res. 2005;40:978-996.

13. Alexander $L$. The double-bind between dialysis patients and their health practitioners. In: Eisenberg L, Kleinman A, eds. The Relevance of Social Science for Medicine. Dordrecht: D. Reidel; 1981:307-329.

14. Murray M, Bodenheimer T, Rittenhouse D, Grumbach K. Improving timely access to primary care: case studies of the advanced access model. JAMA. 2003;289:1042-1046.

15. Murray M, Berwick DM. Advanced access: reducing waiting and delays in primary care. JAMA. 2003;289:1035-1040.

16. Murray M. Answers to your questions about same-day scheduling. Fam Pract Manag. 2005;12:59-64.

17. Donabedian A. The end results of health care: Ernest Codman's contribution to quality assessment and beyond. Milbank Q. 1989;67:233-256; discussion 257-267.

18. Berwick DM. Continuous improvement as an ideal in health care. $N$ Engl J Med. 1989;320:53-56.

19. Berwick DM, Nolan TW. Physicians as leaders in improving health care: a new series in Annals of Internal Medicine. Ann Intern Med. 1998;128:289-292.

20. Bero LA, Grilli R, Grimshaw JM, et al. Closing the gap between research and practice: an overview of systematic reviews of interventions to promote the implementation of research findings. The Cochrane Effective Practice and Organization of Care Review Group. BMJ. 1998;317:465-468.

21. Solberg LI. Guideline implementation: what the literature doesn't tell us. Jt Comm J Qual Improv. 2000;26:525-537.

22. Solberg LI, Brekke ML, Fazio CJ, et al. Lessons from experienced guideline implementers: attend to many factors and use multiple strategies. Jt Comm J Qual Improv. 2000;26:171-188.

23. NHS Centre for Reviews and Dissemination. Getting evidence into practice. Eff Health Care. 1999:5:1-16.

24. Moss F, Garside P, Dawson S. Organisational change: the key to quality improvement. Qual Health Care. 1998;7(Suppl):S1-2.

25. Koeck C. Time for organisational development in healthcare organisations. Improving quality for patients means changing the organisation. BMJ. 1998;317:1267-1268.

26. Solberg LI, Kottke TE, Brekke ML. Quality improvement in primary care: the role of organization, collaboratives, and managed care. In: McLaughlin CP, Kaluzny AD, eds. Continuous Quality Improvement in Health Care: Theory, Implementation, and Applications. $3^{\text {rd }}$ ed. Sudbury, Mass: Jones and Bartlett Publishers; 2005:297-317.

27. Plsek P, Solberg LI, Grol R. Total quality management and continuous quality improvement. In: Jones R, Britten N, Culpepper L, eds. Oxford Textbook of Primary Medical Care. Oxford: Oxford University Press; 2003:490-496.

28. Cohen D, McDaniel RR, Jr, Crabtree BF, et al. A practice change model for quality improvement in primary care practice. J Healthc Manag. 2004;49:155-168; discussion 169-170.

29. Schein E. The Corporate Culture Survival Guide. San Francisco, Calif: Jossey-Bass; 1999.

30. Tallia AF, Lanham HJ, McDaniel RR Jr, Crabtree BF. 7 characteristics of successful work relationships. Fam Pract Manag. 2006;13:47-50.

31. Stroebel CK, McDaniel RR, Jr., Crabtree BF, et al. How complexity science can inform a reflective process for improvement in primary care practices. Jt Comm J Qual Patient Saf. 2005;31:438-446.

32. McDaniel RR Jr, Jordan ME, Fleeman BF. Surprise, surprise, surprise! A complexity science view of the unexpected. Health Care Manage Rev. 2003;28:266-278.

33. Montgomery K. Barriers to reframing surprise as "opportunity" in health care: a commentary on McDaniel, et al. Health Care Manage Rev. 2003;28:284-288; discussion 289-290. 